CLINICAL STUDY

\title{
Geographical correlation between incidence of benign disease and that of cancer of the thyroid among the population of the Rhône-Alpes région of France
}

\author{
Geneviève Sassolas ${ }^{1}$, Zakia Hafdi-Nejjari ${ }^{1}$, Anne Marie Schott ${ }^{2}$, Claire Bournaud ${ }^{1,4}$, Jean Louis Peix ${ }^{3}$, \\ Jacques Orgiazzi ${ }^{3,4}$, Nicole Dutrieux-Berger ${ }^{3}$, Françoise Borson-Chazot ${ }^{1,4}$ and The Group of Pathologists of the \\ Rhône-Alpes Région \\ ${ }^{1}$ Hospices Civils de Lyon, Registre Rhône Alpin des Cancers thyrö̈diens, Fédération d'Endocrinologie et Centre de Médecine Nucléaire Groupement \\ Hospitalier Est, 69677 Bron Cedex, France, ${ }^{2}$ Hospices Civils de Lyon, Pôle d'Information Médicale, Evaluation en Santé, Epidémiologie, 162 Avenue \\ Lacassagne, 69424 Lyon Cedex 03, France, ${ }^{3}$ Hospices Civils de Lyon, Laboratoire d'Anatomie Pathologique, Service d'Endocrinologie et Service de \\ Chirurgie Endocrinienne, Centre Hospitalier Lyon Sud, 69495 Pierre Bénite, France and ${ }^{4}$ Université de Lyon, Université Lyon 1, Inserm U664, F-69008 \\ Lyon, France \\ (Correspondence should be addressed to G Sassolas; Email: registrecancerthyroidien@hotmail.com)
}

(G Sassolas and Z Hafdi-Nejjari contributed equally to this work)

\begin{abstract}
Objective: To analyze, at a population level, the relation between the incidences of benign thyroid diseases in patients submitted to surgery and that of thyroid cancers based on their respective geographical distributions.

Methods: The study included 3169 cases (691 cancers and 2478 benign diseases) operated on in 2002 in the Rhône-Alpes région, which is subdivided into eight départements and 311 cantons.

Results: The total thyroid intervention rate was 54.6/100 000 (23.4 and 86.4), and the annual cancer incidence was 11.9/100 000 (4.7 and 13.8) for men and women respectively. The prevalence of cancer among thyroid surgery was $21.8 \%$ and that of cancer discovered in goiters increased with age (44\% at 60 years). Intervention rates varied from départment to département. In women, the incidence of microcancers was correlated to the thyroid intervention for benign pathologies rate. In men, the incidence of supracentimetric cancers was related to the TIBR. At the canton level, the relative risk of benign diseases was correlated to that of cancers. TIBR and incidence of cancers were higher in urban cantons than in nonurban ones. The density of endocrinologists influenced the prevalence of cancers among all the cases submitted to surgery.

Conclusion: In the Rhône-Alpes population with high rates of thyroid cancer incidence and of thyroid surgery, a number of correlations were found according to gender and tumor size. However, the general incidence of cancer was not directly related to surgical activity. Geographical variability may be related to the heterogeneous medical and pathological practices.
\end{abstract}

European Journal of Endocrinology 162 127-135

\section{Introduction}

That malignant and benign diseases of the thyroid gland could be interconnected was suggested at the beginning of the 20th century in endemic goiter areas such as the Alps where severe iodine deficiency was common, and thyroid cancer morbidity and mortality were high $(1,2)$. This close geographical relationship was reported by Alexis Carrel in 1901 (1), when he wrote in his thesis (translated from French): 'Numbers of benign and malignant tumors oscillate in parallel; where goiter is common, cancer is frequent'. This probably reflected a common view that was later shared by Wegelin who commented on the observations in Switzerland (2). More recently, case-control studies performed in
Switzerland (3) and Northern Italy (4) highlighting long-term residence in iodine-deficient areas with endemic goiter as a risk factor for thyroid cancer provide further evidence for a geographical link between the two. However, despite the increasing interest in the geographical distribution of diseases, no study has been performed recently on the relationships between these pathologies. Since the presentation of more than $10 \%$ of school-age children with thyroid hyperplasia in the Rhône-Alpes in the 1980s, this région of France has been considered as an area of endemic goiter (5). Including around $10 \%$ of the French population, this région encompasses areas varying widely in terms of physical and human geography. Analysis of a regional Thyroid Cancer Registry in 
existence since 1998 has suggested temporal and geographical variations in thyroid cancer incidence (6). By contrast, no recent epidemiological data are available concerning benign thyroid diseases due to the difficulty in assessing their prevalence at the population level. The subpopulation of patients operated on for a benign disease is, however, more easily attainable. Numbers within this population clearly depend on the medical practices leading up to the surgical decision, as is the case for the apparent incidence of thyroid cancer (7).

We hypothesized that the incidence of cancer relates directly to surgical activity. Accordingly, we analyzed the relations between the incidence of benign thyroid diseases in patients submitted to surgery and that of thyroid cancers within 1 year at the population level in the Rhône-Alpes région of France by comparing their respective geographical distributions.

\section{Materials and methods}

\section{Thyroid cancer}

The Thyroid Cancer Registry of the Rhône-Alpes région is a population-based collection of histologically proven incident cases (6). Cases are transmitted from various sources each assuring satisfactory completeness: pathology reports provided by the 30 histopathology laboratories within the Rhône-Alpes région, card index of 103 surgical wards, and hospital claims databases as previously reported (8). Cancers found in the surgical specimens associated with a benign pathology (adenoma or goiter) are recorded as cancers.

A total of 691 incident cases of thyroid cancer were recorded in the year 2002 (169 men and 522 women; Table 1). Mean age at the diagnosis of cancer was 49 years in men and 50 years in women. A total of 4105 incident cases of thyroid cancer were recorded for the period 1998-2004 (966 in men and 3139 in women) and were used for the cantonal geographical distribution.

Table 1 Gender distribution of pathological diagnosis in the 3169 patients who had undergone thyroid surgery in the Rhône-Alpes région in the year 2002.

\begin{tabular}{llll}
\hline & \multicolumn{1}{c}{$\begin{array}{c}\text { Men } \\
\boldsymbol{n}(\%)\end{array}$} & \multicolumn{1}{c}{$\begin{array}{c}\text { Women } \\
\boldsymbol{n}(\%)\end{array}$} & \multicolumn{1}{c}{$\begin{array}{c}\text { Total } \\
\boldsymbol{n}(\%)\end{array}$} \\
\hline Cancers & $169(25.8)$ & $522(20.7)$ & $691(21.8)$ \\
Benign diseases & 486 & 1992 & 2478 \\
Solitary adenomas & $215(44)$ & $690(34.6)$ & $905(36)$ \\
Benign goiters & $218(44)$ & $1000(51)$ & $1218(49.2)$ \\
Hyperthyroidism & $32(6.5)$ & $152(7.6)$ & $184(7.4)$ \\
Others & $21(4.3)$ & $150(7.5)$ & $171(6.9)$ \\
Total thyroid surgery & 655 & 2514 & 3169 \\
\hline
\end{tabular}

\section{Benign thyroid diseases}

For the year 2002, we studied all the surgical interventions related to a benign thyroid disease. The procedure was the same as the one used in the case of cancer in terms of collecting pathology reports and controlling for completeness of data collection. Cases were considered as benign after pathological examination. The same methodology and codification were used by all the pathology laboratories included in the Rhône-Alpes Thyroid Cancer Registry since 1998, allowing also for a homogeneous classification of benign diseases at diagnosis.

In this study, we used the following terminology to describe the benign diseases: 1) solitary adenomas had no hyperplastic surrounding parenchyma. A true adenoma was characterized by an architecture differing from that of the surrounding normal tissue. Adenomas were classified as micro- or macrofollicular, oncocytic, or atypic; 2) benign goiter defined all the multinodular or uninodular goiters; uninodular goiter showed architecture that was the same as that of the surrounding tissue, which was diffusely hyperplastic. This series contained no cases of simple hyperplastic goiter; 3) hyperthyroidism corresponded to Grave's disease, multinodular hyperfunctional goiter, and toxic adenoma; 4) other diagnoses included rare cases of lymphocytic thyroiditis and cysts.

A total of 2478 such patients underwent surgery during 2002, including 486 men and 1992 women. Benign goiters, euthyroid or toxic, represented more than half of the total (Table 1). Mean age at the diagnosis of benign diseases was 52.7 years in men and 50.9 years in women.

\section{Data analyses}

Several age-adjusted rates (using the world population age structure) were calculated as numbers of cases versus population: a) total thyroid intervention rate (TIR); b) thyroid intervention for benign pathologies rate (TIBR); c) thyroid intervention for benign goiter rate (TIGR); d) incidence of all cancer rate; e) rate of incidence of microcancers; and f) rate of incidence of supracentimetric cancers. Moreover, we calculated the prevalence of cancers in all thyroid surgery (\%) and the prevalence of cancers discovered in patients operated on for 'clinical goiter' (comprising goiters considered as benign by histopathology and those associated with a cancer).

\section{Geographical distribution}

All the patients selected for the study lived in the RhôneAlpes région during the study period, and the geographical distribution was based on each patient's place of residence. 


\section{Distribution according to département}

We firstly analyzed the geographical variations of incidence and intervention rates for each of the eight départements (administrative divisions) in the RhôneAlpes région with populations ranging from 294000 to 1616 500. The following age-adjusted incidence rates (using the world population age structure) were calculated as a function of gender: a) the TIR, b) the TIBR, c) the TIGR, and d) the incidence rate of all cancers, and of supracentimetric $(>1 \mathrm{~cm})$ and of microcancers $(\leq 1 \mathrm{~cm})$. The prevalence of cancer among all the interventions was also recorded. The relative risk (RR) within each département of cancer and benign goiter was calculated as the ratio between the values obtained for the département and those obtained for the whole Rhône-Alpes région considered as the reference. The density of endocrinologists for each département (i.e. the number of endocrinologists per 100000 inhabitants) was calculated. All correlations were analyzed using nonparametric Spearman correlation tests.

\section{Distribution according to canton}

There are 311 cantons (electoral districts) in the RhôneAlpes région of which $56(18 \%)$ are urban and 255 $(82 \%)$ are rural or semi-rural, according to the Institut National de la Statistique et des Etudes Economiques. For each canton, we calculated the incidence rate of cancers and interventions for benign diseases for both men and women. To obtain sufficient data concerning cancer incidence per canton, we considered all the cases over the 6-year period from 1998 to 2004. Geographical analysis was performed by a mixed Poisson model as reported previously (6). The covariates introduced into the model with fixed effects were age, physician density (i.e. the number of general practitioners per 1000 inhabitants), and the urban/rural characteristics of the canton. Canton was introduced into the model assuming a random effect and, for each canton, its relative rates (using the whole Rhône-Alpes région as a reference) were estimated using a shrinkage estimator (9) and were mapped using the Arcview 3.1 software (ESRI France).

\section{Results}

Thyroid surgery was performed in a total of 3169 patients during the year 2002 in the Rhône-Alpes région. Overall, $21.8 \%$ (20\% in women and $26 \%$ in men) of all the interventions concerned thyroid cancer. The overall crude TIR was 54.6/100 000 (23.4 and 86.4 for men and women respectively). Standardized rates were as follows: TIBR was 13.8 and 55.0/100 000 and thyroid intervention for benign goiter rate (TIGR) was 6.3 and 27.3/100 000 for men and women respectively.
Table 2 Age group distribution of the percentage of cancers discovered in goiters.

\begin{tabular}{lccc}
\hline Age & $\begin{array}{c}\text { Total number } \\
\text { of cancers }(n)\end{array}$ & $\begin{array}{l}\text { Number of } \\
\text { cancers in } \\
\text { goiters }(n 1)\end{array}$ & $\boldsymbol{n 1 / n ( \% )}$ \\
\hline 0-24 Years & 35 & 2 & 5.7 \\
25-34 Years & 86 & 13 & 15.1 \\
35-44 Years & 135 & 39 & 28.9 \\
45-60 Years & 290 & 102 & 35.2 \\
>60 Years & 145 & 63 & 43.4 \\
Total & 691 & 219 & 31.7 \\
\hline
\end{tabular}

Standardized incidence rates of cancer were 4.7 and $13.8 / 100000$ in men and women respectively.

Of the cancers discovered, the percentage of microcancers $\leq 1 \mathrm{~cm}$ was $40.4 \%$ (30.7\% in men and $44.5 \%$ in women) and that of cancers $\leq 0.5 \mathrm{~cm}$ was $27 \%$. The mean prevalence of cancers discovered inside a goiter represented $31.7 \%$ ( $23 \%$ in men and $34.5 \%$ in women), $60 \%$ of which were microcancers $\leq 1 \mathrm{~cm}(65 \%$ in women and $59 \%$ in men). These percentages differed according to the age groups (Table 2). Four percent of the cancers coexisted with hyperthyroidism, and 12\% were in the vicinity of benign adenomas in the same patient. Overall, cancers were found in $15 \%$ of all the patients operated on for 'clinical goiter'.

\section{Distribution according to département}

The TIR, TIBR, TIGR, and the incidence of cancers varied widely among the départements but were consistently three times higher in women than in men (Fig. 1 and Table 3). The prevalence of cancers found among the total number of surgical interventions for thyroid disease (benign and malignant) was variable ranging from $13 \%$ in Haute-Savoie, the département with the highest TIR, to $27 \%$ in both the Rhône

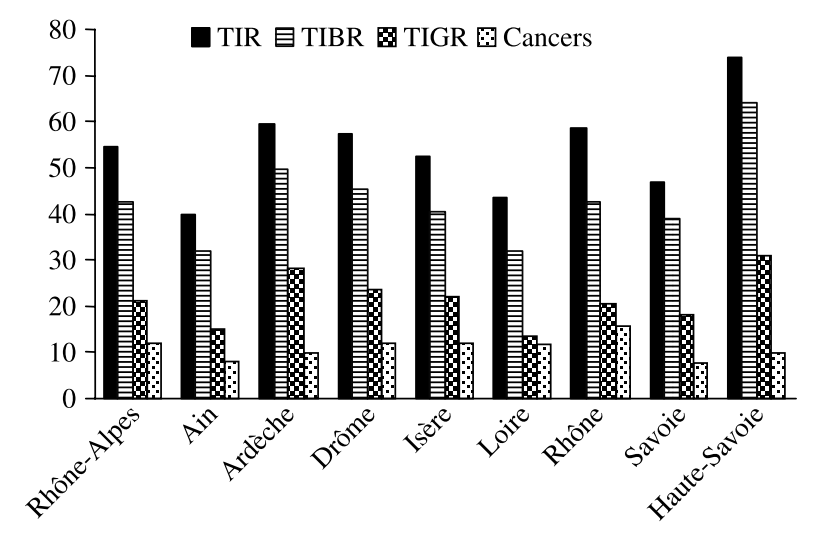

Figure 1 Distribution among each département of the thyroid intervention rate (TIR), thyroid intervention benign rate (TIBR), thyroid intervention goiter rate (TIGR), and the incidence rates of cancers (crude rates). Rhône-Alpes represents the mean values of the whole région. 
Table 3 Distribution according to gender of the thyroid intervention rate (TIR), thyroid intervention for benign pathologies rate (TIBR), and thyroid intervention for benign goiter rate (TIGR). The incidence rates of cancers, microcancers, and supracentimetric cancers, and the prevalence of cancers in all interventions are also shown (age-adjusted incidence rates).

\begin{tabular}{|c|c|c|c|c|c|c|c|c|c|c|c|c|c|}
\hline & \multicolumn{2}{|c|}{ TIR } & \multicolumn{2}{|c|}{ TIBR } & \multicolumn{2}{|c|}{ TIGR } & \multicolumn{2}{|c|}{$\begin{array}{l}\text { Incidence } \\
\text { of cancer }\end{array}$} & \multicolumn{2}{|c|}{$\begin{array}{l}\text { Incidence of } \\
\text { microcancers }\end{array}$} & \multicolumn{2}{|c|}{$\begin{array}{c}\text { Incidence of } \\
\text { supracentimetric } \\
\text { cancers }\end{array}$} & \multirow{2}{*}{$\begin{array}{c}\begin{array}{c}\text { Prevalence } \\
\text { of cancers } \\
(\%)\end{array} \\
\text { Total }\end{array}$} \\
\hline & M & $\mathrm{F}$ & $\mathrm{M}$ & $\mathrm{F}$ & $M$ & $\mathrm{~F}$ & M & $\mathrm{F}$ & M & $\mathrm{F}$ & M & $\mathrm{F}$ & \\
\hline Rhône-Alpes & 18.7 & 68.3 & 13.8 & 55.0 & 6.3 & 27.3 & 4.7 & 13.8 & 1.5 & 6.2 & 3.3 & 7.6 & 21.8 \\
\hline Ain & 12.8 & 49.3 & 10.3 & 39.7 & 4.0 & 19.4 & 2.5 & 9.7 & 1.0 & 3.5 & 1.6 & 6.6 & 20 \\
\hline Ardèche & 18.8 & 74.4 & 14.6 & 63.1 & 5.2 & 39.1 & 4.1 & 11.2 & 1.6 & 6.0 & 2.1 & 4.3 & 16.5 \\
\hline Drôme & 15.7 & 61.0 & 18.0 & 49.5 & 8.6 & 26.3 & 6.2 & 11.9 & 2.4 & 5.5 & 3.5 & 5.3 & 20.9 \\
\hline Isère & 17.2 & 66.9 & 12.8 & 52.9 & 6.5 & 29.6 & 6.2 & 14.2 & 1.9 & 6.6 & 3.1 & 7.8 & 22.7 \\
\hline Loire & 14.0 & 54.4 & 10.9 & 39.4 & 4.3 & 16.9 & 3.3 & 15.3 & 1.2 & 5.8 & 2.4 & 9.1 & 27 \\
\hline Rhône & 19.5 & 72.3 & 13.3 & 53.9 & 5.8 & 26.5 & 5.9 & 18.5 & 1.7 & 7.7 & 4.4 & 11.0 & 27 \\
\hline Savoie & 17.2 & 53.5 & 11.6 & 46.9 & 6.0 & 21.2 & 5.5 & 6.7 & 0.9 & 3.1 & 4.2 & 2.6 & 17 \\
\hline Haute-Savoie & 24.9 & 82.5 & 20.9 & 87.1 & 9.8 & 34.6 & 4.0 & 10.2 & 0.8 & 6.6 & 3.3 & 3.9 & 13 \\
\hline
\end{tabular}

$M$, male; F, female.

département, the one with the second highest TIR, and the Loire département, the one with a low TIR (Table 3). The prevalence of cancers and that of microcancers in all thyroid surgery were strongly correlated $(r=0.80$; $P=0.02$ ).

Figure 2 shows the variability in the incidence rates of supra- and infracentimetric cancers between départements. Rates also differed between men and women, with rates of supracentimetric cancers being higher than those of the microcancers in men in most départements. Incidence rates of infracentimetric cancers are higher in women than in men corresponding to the distribution of microcancers, which are globally higher in women than in men (43 vs 33\%).

The relationships between cancer incidence and TIBR, microcancer incidence and TIBR and TIGR, and the supracentimetric cancer incidence and TIGR are shown in Figs 3-5. The prevalence of cancers in all the goiters operated on and the RR of benign goiter and of cancer are shown in Fig. 5. We found no correlation between the incidence rates of all cancers and TIBR in men or in women (Fig. 3). However, a significant correlation was found between the incidence rates of microcancers and TIBR, but it was found only in women $(r=0.71 ; P=0.05$; Fig. 4). In men, we found a trend toward a correlation between the incidence of supracentimetric cancers and TIGR $(r=0.57 ; P=0.15$; Fig. 5A), which was not found in women (data not shown). A significant correlation was found between the prevalence of cancers discovered in all cases of clinical goiter and TIGR ( $r=0.71 ; P=0.05$; Fig. 5B). The respective risks of benign pathology on the one hand and those of the cancer on the other hand, calculated as described above, were evaluated with respect to each département. RRs of cancer and benign goiter showed a relation only in men $(r=0.55 ; P=0.17$; Fig. 5C). This correlation was highly significant when the data from Haute-Savoie département were removed $(r=0.85 ; P=0.02)$.
The density of endocrinologists varied from 0.3 in the Ardèche département to 4.5/100 000 in the Rhône département. It showed no relation with the various intervention rates, but in men it showed a significant relation with the prevalence of cancers found in all operations $(r=0.68 ; P<0.05)$ and to the incidence of supracentimetric cancers $(r=0.71 ; P<0.05)$. We also found a trend toward a correlation between the density of endocrinologists and the incidence rates of all cancers in men and women ( $r=0.52$ and 0.56 respectively) but not with the incidence rates of microcancers in men and women.

\section{Distribution according to canton}

The cantons were divided into urban $(41 \%$ of the whole regional population) and nonurban (rural and semirural) $(59 \%$ of the whole regional population). Differences between rural and urban cantons were statistically significant. Both cancer incidence and TIBR were higher in urban cantons than in nonurban cantons (Table 4). Cancer incidence was $28 \%$ lower in men (relative rate $4.3 / 6=0.72$ ) and $15 \%$ lower in women (relative rate $14.4 / 17=0.85$ ) in rural cantons compared with in urban cantons. The TIBR was $10 \%$ lower in rural cantons than in urban cantons $(22 \%$ in men (relative rate rates $15.4 / 19.8=0.78$ ) and $4 \%$ in women $($ relative rates $=66.4 / 68.8=0.96)$ ).

The Poisson mixed model with adjustment on all covariates confirmed these results. General practitioner density did not appear to have a significant effect on the incidence of benign and malignant diseases, whether in men or in women. There was a large variability in the intervention and incidence rates of benign and malignant diseases respectively between the cantons varying from -52 to $+110 \%$ for TIBR and from -40 to $+70 \%$ for cancer incidence. Relations between benign pathology and cancers according to canton were evaluated in terms of risk for both. A weak yet 

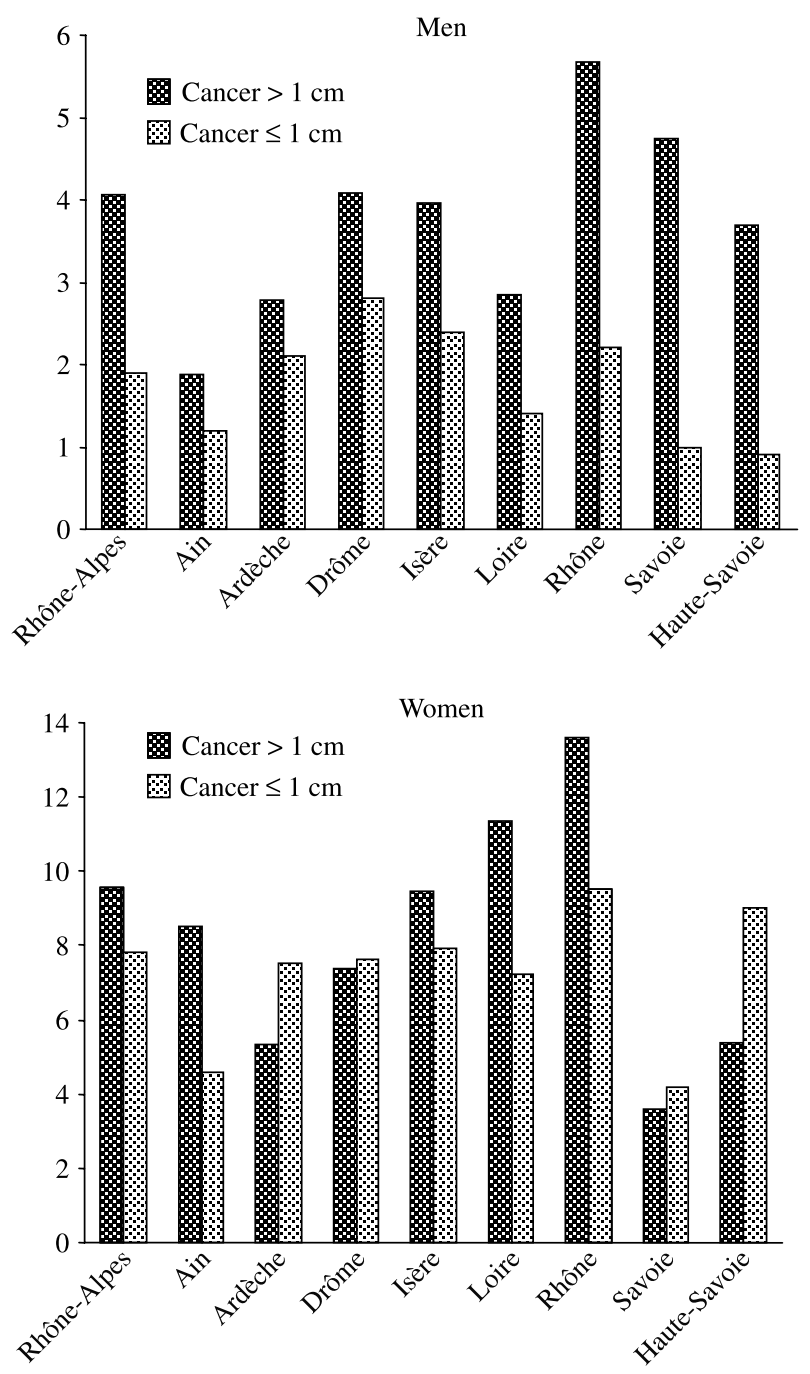

Figure 2 Distribution of incidence rates of supra- and infracentimetric cancers in men and women according to département.

significant correlation was found only in men $(r=0.26$; $P<0.05)$. We also found a correlation between the risks of benign pathology in both men and women $(r=0.35 ; P<0.05)$.

Figure 6 shows the variability of incidence rates of cancer and of TIBR in men within each canton after adjustment for men's age and the rural/urban characteristic of the canton.

\section{Discussion}

Increasing incidence in thyroid cancer has been reported in various countries (10-15). Increased diagnostic activity leading to an increased incidence of small cancers has been advocated as one of the possible causes of this epidemiological observation $(10,14)$. Incidental cancers detected in surgical specimens have recently been reported to represent a third of all cancers (6). This was confirmed in the present study since $30 \%$ of the cancers were discovered within goiter and $15 \%$ of all the cases of 'clinical goiter' were found to coexist with a cancer. The prevalence of cancers discovered in goiters increased with age, reaching $41.8 \%$ in patients older than 60 years. We have previously reported that the incidence of thyroid cancer dramatically increased with age (6). All these data are in accordance with the well-known effect of age on the incidence of thyroid pathology. In the present study, the prevalence of incidental cancers is probably underestimated since partial thyroidectomy was performed in more than $20 \%$ of the patients. These data are in keeping with the notion that a personal history of benign pathology, namely a goiter, is a risk factor for thyroid cancer, as has been reported previously in a number of case-control studies (16-23).

The present study used a novel population approach to investigate the relations between benign disease and cancer of the thyroid. We hypothesized that within a defined geographical area, the incidence of cancer would relate to surgical activity in particular that concerning benign goiter, mostly multinodular.
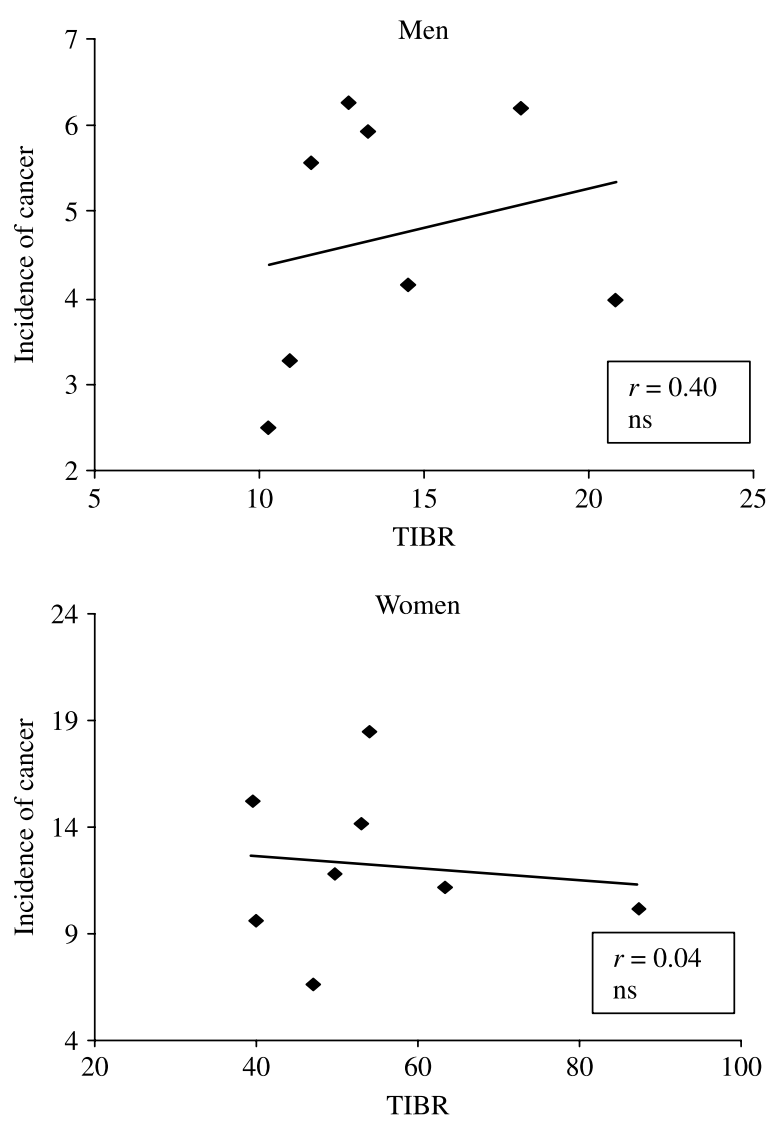

Figure 3 Correlations between TIBR and incidence of cancers in men and women according to département (nonparametric Spearman correlation tests). 

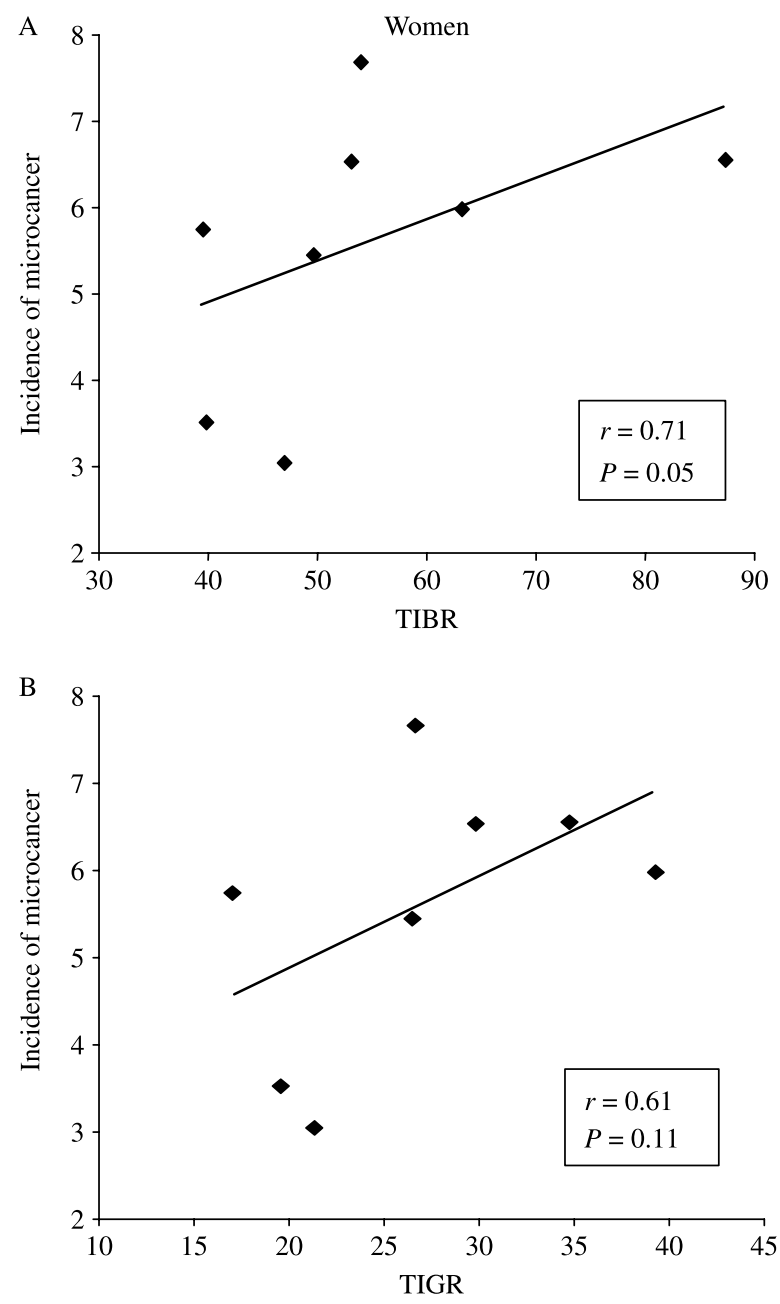

Figure 4 Correlations between TIBR (A), TIGR (B), and incidence of microcancers in women (nonparametric Spearman correlation tests).

In 2002, the high rates of surgical procedures on the thyroid (54.6/100 000 person/year) were reported in the Rhône-Alpes, a région of France with six million inhabitants and formerly considered a zone of endemic goiter. This can be attributed to a high incidence of goiter, responsible for $50 \%$ of surgery performed on the thyroid for a benign disease. In 2002, the incidence of thyroid cancer was 11.9/100 000, and the prevalence of cancers found during surgery was $21.8 \%$. These results differ from those reported for the same period in the USA where the total TIR was 19.7/100 000 and the percentage of cancers found was $33 \%(10,24)$. As the cancer incidence rates between the USA and France are comparable $(6,10)$, the differences in the intervention rate for thyroid benign disease could explain these discrepancies. It is to be noted that in the Rhône-Alpes region, the incidence of thyroid cancer was stable between 2001 and 2006 (6).

In order to investigate the existence of a link between benign and malignant diseases, we studied the geographical distribution of both in the administrative areas of varying sizes, i.e. départements and cantons, within the Rhône-Alpes région of France.

Differences between départements were found when the prevalence of cancers discovered in all the operated
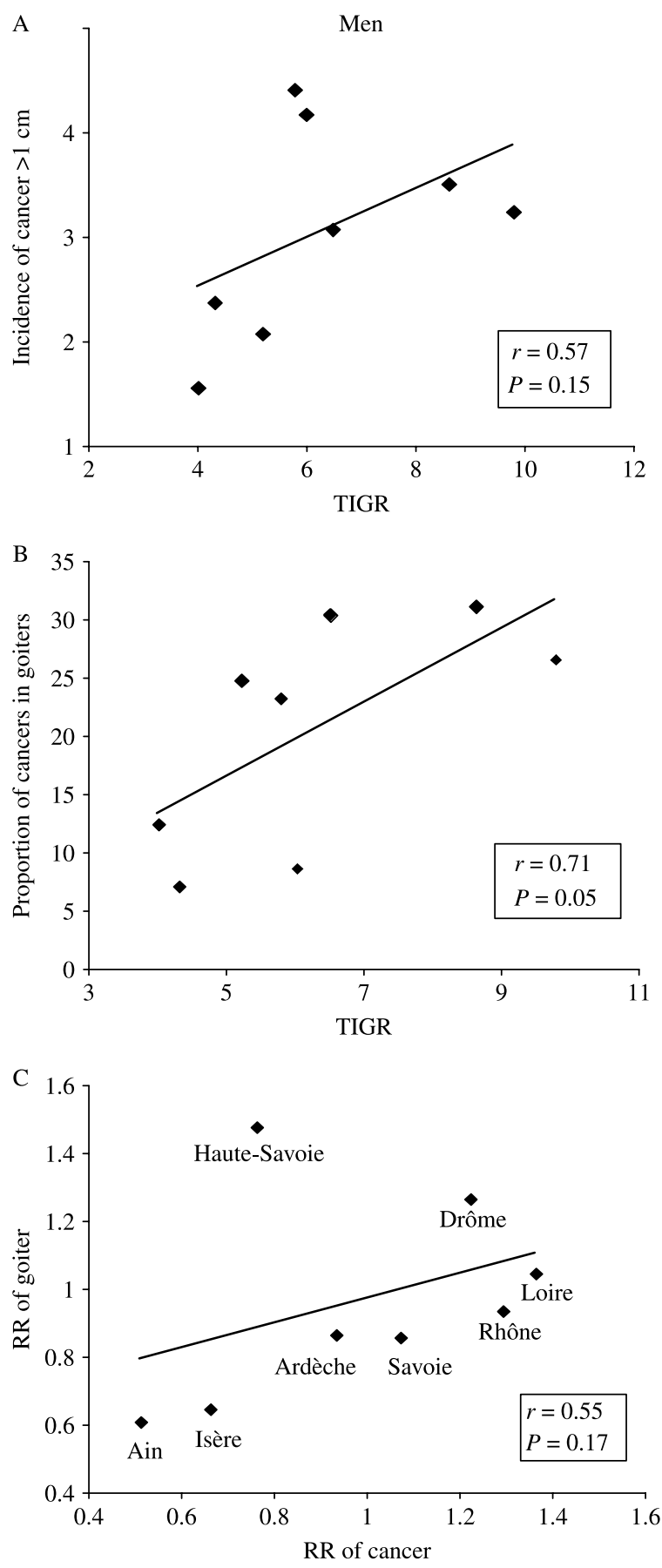

Figure 5 Correlations between TIGR and incidence of supracentimetric cancers $(A)$, between TIGR and prevalence of cancers in interventions for clinical goiter (B), and relative risks (RRs) of cancer and goiter (C) in men (nonparametric Spearman correlation tests) according to département. 
Table 4 Incidence rates of benign diseases and cancers/100 000 person-year according to urban/rural characteristics of the canton.

\begin{tabular}{|c|c|c|c|c|}
\hline & \multicolumn{2}{|c|}{$\begin{array}{l}\text { Incidence rates in } \\
\text { urban cantons }\end{array}$} & \multicolumn{2}{|c|}{$\begin{array}{l}\text { Incidence rates in rural } \\
\text { and semi-rural cantons }\end{array}$} \\
\hline & Cancers & Benign & Cancers & Benign \\
\hline Men & 6 & 19.8 & 4.3 & 15.4 \\
\hline Women & 17 & 68.8 & 14.4 & 66.4 \\
\hline Total & 11.8 & 45.5 & 9.4 & 41.1 \\
\hline
\end{tabular}

cases was considered. This prevalence was higher in the university hospitals than in the general nonacademic ones indicating a preoperative selection directed toward cancer.

Although we found together a high rate of surgical intervention and a high incidence of thyroid cancer, our analysis did not reveal a clear relation between surgical intervention rates for benign diseases and incidence of cancer. However, some relations could be seen when the results were analyzed according to gender and tumor size. Indeed, our results suggest a link between cancer and benign disease in men. At the département level, a significant correlation was found between the prevalence of cancer discovered coexisting with goiter and the intervention rate for benign goiter. A trend toward a correlation was found between the incidence of supracentimetric cancer and surgery for benign goiter. Concordantly, a weak but significant relation was shown between cancer and benign disease at the canton level. In women, a significant relation was found between surgery for benign disease and the incidence of microcancers, which represent a high proportion $(45 \%)$ of all cancers, most of which were located within the goiter. Generally, microcancer incidence (or in situ cancer) is commonly considered as a strong indicator of medical intervention. The present study shows a parallel between the incidence of microcancers in women and the rate of thyroidectomy.

The cantonal study revealed no zone of over-incidence of benign and malignant diseases occurring concomitantly. The existence of any environmental risk factor(s)
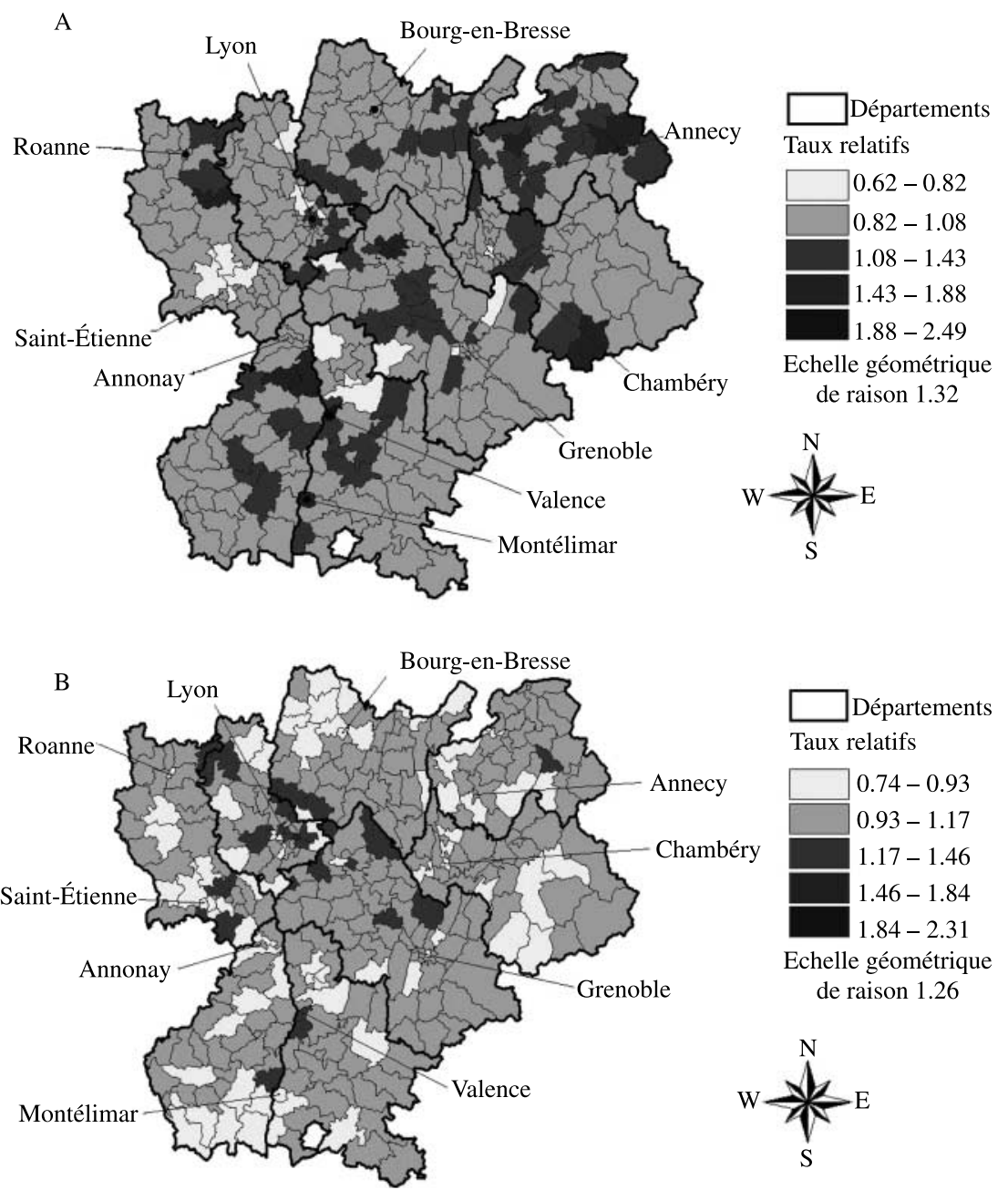

Figure 6 Distribution of relative rates of benign $(A)$ and cancer $(B)$ incidences in men according to canton. The covariate introduced in the model is the urban/rural characteristic of the canton. 
common to benign and malignant diseases in a particular zone of residence would have induced a strong link in incidences at the canton level. As this was not the case, the strong intervention of any common environmental factor may be excluded and the risks in relation to different environmental factors specific to urban and nonurban cantons can be considered as having, if any, a very limited influence. Indeed, the differences in incidence of either class of diseases are significant only in men. The modestly lower incidence of both benign and malignant diseases in rural zones argues against agricultural products having any noticeable influence. The weak over-incidence in urban cantons could be related to factors other than environmental factors, namely the proximity to healthcare services with an increased density in urban cantons compared with rural cantons.

Our data suggested no influence of density of general practitioners at the canton level. Density of endocrinologists did not influence the total rate of intervention on the thyroid at the département level. It did, however, relate to the prevalence of cancers found in surgical interventions indicating an effect of selection. Since endocrinologists practice in urban zones, this may explain the weak over-incidence compared with rural zones corresponding to the ease of access, especially for men who consult less often than women and mainly for 'clinical' diseases.

This epidemiological study based on a 1-year observation has several limitations. First, the histopathological examinations were performed by a large number of pathologists working in 30 different laboratories. A revision of all the specimens by the same pathologist or group of pathologists was unrealistic. Secondly, the differential diagnosis of cancers and adenomas can be difficult. In the Rhône-Alpes région, the most doubtful cases are usually sent for revision to one of us (N D B), which consequently leads to at least some homogeneity. Thirdly, while extensive pathological examination of surgical specimens was performed for any cases of goiter considered as benign, the discovery of microcancers highly depends on the number of slides used, which may occasionally differ between laboratories. The strong correlation between the prevalence of cancers and that of microcancers among all thyroid surgery suggests, however, a reasonable homogeneity in the pathology procedures within the participants to Rhône-Alpes Thyroid Cancer Registry. Nevertheless, pathology practices may clearly influence the prevalence of cancers. Other hypotheses to explain the variability of incidence rates and prevalence of cancers between départements may include rurality with less favorable access to specialized care, geographical diversity, and iodine supply during childhood.

The choice of the benign disease constitutes the major drawback of this study. It was decided that all cases submitted to surgery and classified as benign by histopathology would constitute the core of this group since it appeared unrealistic to record all the consultations for thyroid disease in the region. We worked on the assumption that all the cases submitted to surgery corresponded to the prevalence of all the thyroid diseases. On this basis, medical practices are clearly the main determinants of the incidence of cases submitted to surgery. The decision to operate was based on local discomfort, hyperthyroidism in nearly $8 \%$ of the cases, or suspicion of an associated cancer that is difficult to be eliminated by preoperative examination. To our knowledge, there exist no consensus criteria for cases, clinically considered as benign, to be referred for surgery. Decision for surgery depends on the patient (where they live, how their illness is perceived, and their consent to operate), the physician, general practitioner or endocrinologist, and principally the surgeon. However, most surgeons working in our region have been trained in the same academic hospitals and participate in regional meetings chaired by one of us (J L P), a member of the French association of endocrine surgery. The role of the type of medical practice has been mentioned above. We were unable to identify other factors that might interfere with the incidence of malignant or benign diseases. Other limitations of the study may be related to the choice of the study areas with precise population sizes. Indeed, the small number of départements (8) could limit the significance of the differences observed. Cantons may also be too small to contain sufficient numbers of patients.

Altogether, these limitations could explain the discrepancy in results obtained in some départements such as the Haute-Savoie, where the very high risk of benign disease (mainly goiter) is associated with a cancer incidence that is lower than the regional average, both in men and in women. Such limitations are intrinsic to a population study performed in real life situations and may also explain the lack of a comparable study in the literature.

In conclusion, in the Rhône-Alpes population with high rates of thyroid cancer incidence and of thyroid surgery, a number of correlations were found according to gender and tumor size. However, the general incidence of cancer was not directly related to surgical activity. Geographical variability may be related to the heterogeneous medical and pathological practices.

\section{Declaration of interest}

There is no financial relationship that could lead to a conflict interest.

\section{Funding}

This research received funding from Inserm and Institut National de Veille Sanitaire. Appel à projets 2004 «Etude sur les facteurs de risque des cancers différenciés de la thyrö̈de» and from la Ligue Nationale Contre le Cancer, Fédération du Rhône 2004: "Allocation de recherche». 


\section{Acknowledgements}

The authors would like to thank Dr Nadine Bossard, Mr Laurent Remontet, and $\mathrm{Mr}$ Aurélien, Belot Laboratoire de Biostatistique, Université Lyon 1, France, for their active contributions to the present study including the distributions of incidences at the canton level and for the continuous help and support they provided to the Registre Rhône-Alpin des Cancers Thyroidiens. We would like to thank all the histopathology laboratories, the surgical wards, and the medical information facilities of each département of the Rhône-Alpes région for their collaboration.

\section{References}

1 Carrel A. Le goitre cancéreux. Thèse de doctorat en médecine Lyon, Editeur. Paris: Librairie JB Baillière, 1900.

2 Wegelin C. Malignant disease of the thyroid gland and its relation to goiter in men and animals. Cancer Review 19283 297-313.

3 Levi F, Franceschi S, La Vecchia C, Negri E, Gulie C, Duruz G \& Scazziga B. Previous thyroid disease and risk of thyroid cancer in Switzerland. European Journal of Cancer 199127 85-88.

4 Fioretti F, Tavani A, Gallus S, Franceschi S, Negri E \& La Vecchia C. Case-control study of thyroid cancer in Northern Italy: attributable risk. International Journal of Epidemiology 199928 626-630.

5 Mornex R. Enquête sur la prévalence du goître en France. Bulletin de l'Académie Nationale de Médecine 1987171 301-306.

6 Sassolas G, Hafdi-Nejjari Z, Remontet L, Bossard N, Belot A, Berger-Dutrieux N, Decaussin-Petrucci M, Bournaud C, Peix JL, Orgiazzi J \& Borson-Chazot F. Thyroid cancer: is the incidence rise abating? European Journal of Endocrinology 2009160 71-79.

7 Leenhardt L, Bernier MO, Boin-Pineau MH, Conte Devolx B, Maréchaud R, Nicolli-Sire P, Nocaudie M, Orgiazzi J, Schlumberger M, Wémeau JL, Chérié-Challine L \& De Vathaire F. Advances in diagnostic practices affect thyroid cancer incidence in France. European Journal of Endocrinology 2004150 133-139.

8 Hafdi-Nejjari Z, Couris CM, Schott AM, Perrot L, Bourgoin F, Borson-Chazot F \& Sassolas G. Role of hospital claims databases from care units for estimating thyroid cancer incidence in the Rhône-Alpes region of France. Revue d'Épidémiologie et de Santé Publique 200654 391-398.

9 Goldstein H. Multilevel Statistical Methods, pp 22-103. London: Hodder Arnold, 2003.

10 Davies L \& Welch HG. Increasing incidence of thyroid cancer in the United States, 1973-2002. Journal of the American Medical Association 2006295 2164-2167.

11 Liu S, Semenciw R, Ugnat AM \& Mao Y. Increasing thyroid cancer incidence in Canada, 1970-1996: time trends and age-periodcohort effects. British Journal of Cancer 200185 1335-1339.
12 Reynolds RM, Weir J, Stockton DL, Brewster DH, Sandeep TC \& Strachan MW. Changing trends in incidence and mortality of thyroid cancer in Scotland. Clinical Endocrinology 200562 156-162.

13 Colonna M, Grosclaude P, Remontet L, Schwartz C, Mace-Lesech J, Velten M, Guizard AV, Tretarre B, Buemi A, Arveux P \& Esteve J. Incidence of thyroid cancer in adults recorded by french cancer registries (1978-1997). European Journal of Cancer 200238 1762-1768.

14 Colonna M, Guizard AV, Schvartz C, Velten M, Raverdy N, Molinie F, Delafosse P. Franc B \& Grosclaude P. A time trend analysis of papillary and follicular cancers as a function of tumour size: a study of data from six cancer registries in France (19832000). European Journal of Cancer 200743 891-900.

15 Mellemgaard A, Knudsen N, Jorgensen T \& Perrild H. Review of thyroid cancer cases among patients with previous benign thyroid disorders. Thyroid $2000 \mathbf{1 0} 697-700$.

16 McTiernan AM, Weiss NS \& Daling JR. Incidence of thyroid cancer in women in relation to previous exposure to radiation therapy and history of thyroid disease. Journal of the National Cancer Institute 198473 575-581.

17 Preston-Martin S, Bernstein L, Pike MC, Maldonado AA \& Henderson BE. Thyroid cancer among young women related to prior thyroid disease and pregnancy history. British Journal of Cancer 198755 191-195.

18 Preston-Martin S, Jin F, Duda MJ \& Mack WJ. A case-control study of thyroid cancer in women under age 55 in Shanghai (People's Republic of China). Cancer Causes \& Control 1993 4 431-440.

19 D’Avanzo B, La Vecchia C, Franceschi S, Negri E \& Talamini R. History of thyroid diseases and subsequent thyroid cancer risk. Cancer Epidemiology, Biomarkers \& Prevention 19954 193-199.

20 Ron E, Kleinerman RA, Boice JD, LiVolsi VA, Flannery JT \& Fraumeni JF. A population-based case-control study of thyroid cancer. Journal of the National Cancer Institute 198779 1-12.

21 Memon A, Varghese A \& Suresh A. Benign thyroid disease and dietary factors in thyroid cancer: a case control study in Kuwait. British Journal of Cancer 200286 1745-1750.

22 Kolonel LN, Hankin JH, Wilkens LR, Fukunaga FH \& Hinds MW. An epidemiologic study of thyroid cancer in Hawaï. Cancer Causes and Control $19901223-234$.

23 Franceschi S, Preston Martin S, Dal Maso L, Negri E, La Vecchia C, Mack WSJ, McTiernan A, Kolonel L, Mark SD, Mabuchi K, Jin F, Wingren G, Galanti R, Hallquist A, Glattre E, Lund E, Levi F, Linos D \& Ron E. A pooled analysis of case-control studies of thyroid cancer: IV benign thyroid diseases. Cancer Causes $\mathcal{E}$ Control 199910 583-595.

24 Schwartz A. Thyroid surgery: who should do it? How should it be done? Thyroid 200515 185-187.

Received 25 August 2009

Accepted 28 September 2009 